УДК 159.9.07

\title{
СИТУАТИВНО-ЛИЧНОСТНАЯ СТРУКТУРА ПЕРЕЖИВАНИЯ ВРЕМЕНИ СТУДЕНТАМИ
}

\author{
Широкая Марина Юрьевна \\ к.психол.н., доцент \\ ФГБОУ ВО «Московский государственный университет \\ им. М.В. Ломоносова»
}

\begin{abstract}
Аннотация: В статье представлены результаты эмпирического исследования, посвященные выявлению особенностей переживания времени своей жизни, учебной деятельности и переживания времени в условиях его дефицита у студентов. Респондентами выступили 69 учащихся вуза.

Представлена трехфакторная ситуативно-личностная структура переживания времени у студентов, представляющая сочетание переживания разных масштабов времени жизнедеятельности - времени жизни (временная перспектива), отношения ко времени учебы (психологическое время) и ситуативно-обусловленные переживания дефицита времени (тайм-синдром).
\end{abstract}

Ключевые слова: Переживание времени, временная перспектива, психологическое время, дефицит времени, тайм-синдром.

\section{SITUATIONAL-PERSONAL STRUCTURE OF STUDENTS ' TIME}

\section{Shirokaya Marina Yr.}

\begin{abstract}
The article presents the results of an empirical study devoted to identifying the features of experiencing the time of one's life, learning activities and experiencing time in conditions of its deficit in students. The respondents were 69 students.

The three-factor situational and personal structure of students' experience of time is shown, which is a set of experiences of different scales of life activity-life time (time perspective), attitudes to school time (psychological time) and situationally conditioned experiences of time deficit (time syndrome).
\end{abstract}




\section{ЛОМОНОСОВСКИЕ ЧТЕНИЯ. АКТУАЛЬНЫЕ ВОПРОСЫ ФУНДАМЕНТАЛЬНЫХ И ПРИКЛАДНЫХ ИССЛЕДОВАНИЙ}

Key words: Time experience, time perspective, psychological time, time scarcity, time syndrome.

Переживание как часть внутренней жизни человека и рефлексивная функция сознания занимает одно из центральных мест и важнейших предметов исследования в психологии личности $[2,6]$. Василюк дал такое определение переживанию: «Переживание... понимается в его противопоставлении объективному знанию: переживание - это особое, субъективное, пристрастное отражение, причем отражение не окружающего предметного мира самого по себе, а мира, взятого в отношении к субъекту, с точки зрения предоставляемых им (миром) возможностей удовлетворения актуальных мотивов и потребностей субъекта» [2, с. 11]. В рамках индивидуального подхода к работающему человеку внимание акцентировано на переживаниях личности различных сторон своей деятельности, в том числе обусловленных стремлением сохранить свое професиональное и психическое здоровье и повысить качество жизни. Вместе с тем, в современных условиях мировой пандемии изучение рефлексии при осуществлении деятельности является дополнительным и перспективным ресурсом для оказания психологической помощи в специфических условиях всеобщей дистанционной работы.

Переживание времени рассматривается как процесс, отражающий субъективное отношение человека к важным событиям его жизни [4]. В трудовой деятельности при наличии сроков и/или ограниченного времени, так называемого дефицита времени, переживание времени становится осознанным процессом, направленным на достижение поставленных целей, где выполнение задания в срок рядоположено с задачей выполнить работу. Важно подчеркнуть, что задача «выполнить работу» не содержит жесткого временного континуума. Вместе с этим и качество работы может быть разным: высоким, средним и даже низким. А задача «в срок» «в пространстве времени» всегда является фиксированной точкой, «не попадание» в которую, приводит, в лучшем случае, к снижению качества работы/учебы, в худшем - к срыву поставленной цели и отсутствию результата работы. Таким образом, фактор времени играет первостепенную координирующую роль при осуществлении выполнения тех или иных задач во многих видах трудовой деятельности [7].

Учебная деятельность студентов является насыщенной и учебными заданиями, и временными сроками. Переживание времени, включая время, 
посвященное выполнению учебных задач и время, свободное от учебы, у студентов выражено значительно и, зачастую, окрашено негативными эмоциями из-за нехватки свободного времени. Изучение переживания времени студентами показало, что его особенности претерпевают изменения в процессе профессиональной подготовки и связаны с ценностно-смысловой структурой личности [1]. Однако целесообразно рассмотреть переживание времени в трудных ситуациях и переживание времени, обусловленное и событиями всей жизни, и психологическими особенностями человека.

Целью нашего исследования было выявление специфики переживания времени студентами в их учебной деятельности. Переживание времени студентами мы рассматривали на двух уровнях: личностном и ситуативном. Так, переживание времени на личностном уровне обеспечило изучение (1) временной перспективы как отношения к своему прошлому, настоящему и построения своего будущего и (2) психологического времени - отношения личности к своему времени жизнедеятельности. На ситуативном уровне, отражающем более ограниченный масштаб, охватывающий отношение личности к своему актуальному времени - переживание времени в ситуации дефицита времени, обусловленной спецификой учебной деятельности студентов. При помощи разноуровневых показателей отношения студентов ко времени была выявлена ситуативно-личностная структура переживания времени.

Наше исследование проводилось в МГУ имени М.В. Ломоносова (филиал в г. Баку). Всего приняли участие 64 студента, из них 25 юношей, 39 девушек. Средний возраст составил 19,4 года. Средний балл - 4,05. 2-ой курс - 37 чел., 3ий курс - 27 чел. Студенты, принявшие участие в нашем исследовании, равномерно распределены по разным факультетам.

Специфика выборки студентов состояла в объективных причинах влияния переживания дефицита времени на выполнение учебных задач: учебные занятия в филиале проводят преподаватели из г. Москвы вахтовым методом, прослушивание одного курса сопровождается ежедневными домашними заданиями. Такая организация учебной работы и связанная с ней временная нагрузка предполагает актуализацию отношения студентов к своему времени и его ресурсам. Поэтому изучение переживания времени учебы и времени на отдых у наших респондентов - проблема актуальная и, можно сказать, злободневная. 
Для выявления ситуативно-личностной структуры переживания времении был использован следующий пакет диагностических методов: методики «Временная перспектива» [5], «Шкалы психологического времени» [4], «Таймсиндром менеджера» (адаптированная к выборке студентов) [3]. Обработка результатов проводилась при помощи статистического пакета SPSS (22 версия). Были использованы описательная статистика, факторный анализ и вторичная факторизация данных для выявления более крупных факторов переживания времени (метод главных компонент с последующим VARIMAX вращением).

Описательная статистика показателей переживания времени представлена в таблице 1.

Показатели временной перспективы имеют относительно сглаженный профиль, по сравнению с профилем, полученным в исследованиям Ф. Зимбардо. На рисунке 1 даны показатели временной перспективы у обследованной выборки студентов и выборки, представленной у Ф. Зимбардо [5].

Показатели шкал психологического времени смещены в область переживания напряженности учебного времени. Наиболее выражено переживание насыщенности (5,17 баллов) и ограниченности своего времени (4,92 балла).

Таблица 1

Описательная статистика показателей переживания времени у всей выборки студентов $(\mathrm{N}=64)$

\begin{tabular}{|c|c|c|c|c|}
\hline Показатели & $\min$ & $\max$ & $\mathbf{X}$ & $\sigma$ \\
\hline \multicolumn{5}{|c|}{ Временная перспектива } \\
\hline Негативное прошлое & 1,6 & 4,5 & 2,92 &, 74 \\
\hline Позитивное прошлое & 1,1 & 4,78 & 3,43 &, 72 \\
\hline Гедонистическое настоящее & 2 & 4,67 & 3,56 &, 57 \\
\hline Фаталистическое настоящее & 1,33 & 4,44 & 2,71 &, 65 \\
\hline Будущее & 2,23 & 4,92 & 3,6 &, 59 \\
\hline \multicolumn{5}{|c|}{ Шкалы психологического времени } \\
\hline Медленное - быстрое & 1 & 7 & 4,30 & 1,76 \\
\hline Пустое - насыщенное & 2 & 7 & 5,17 & 1,33 \\
\hline Плавное - скачкообразное & 2 & 7 & 4,86 & 1,56 \\
\hline Приятно - неприятное & 1 & 7 & 3,63 & 1,42 \\
\hline
\end{tabular}




\begin{tabular}{|l|c|c|c|c|}
\hline Непрерывистое - прерывистое & 1 & 7 & 4,28 & 1,58 \\
\hline Сжатое - растянутое & 1 & 7 & 3,83 & 1,73 \\
\hline Однообразное - разнообразное & 1 & 7 & 3,98 & 1,77 \\
\hline Ограниченное - неограниченное & 1 & 7 & 2,94 & 1,82 \\
\hline Цельное - раздробленное & 1 & 7 & 3,58 & 1,69 \\
\hline Беспредельное - ограниченное & 1 & $\underline{7}$ & 4,92 & 1,36 \\
\hline \multicolumn{2}{|c|}{ Тайм-синдром (переживание дефицита времени) } \\
\hline Переживание ограниченности времени в ДВ & 3 & 12 & 8,86 & 2,40 \\
\hline Переживание напряженности при ДВ & 3 & 12 & 9,36 & 2,59 \\
\hline Эмоциональность переживания ДВ & 3 & 12 & 9,33 & 2,18 \\
\hline Продуктивность использования личного времени & 5 & 12 & 9,23 & 1,59 \\
\hline Переживание зависимости от работы (учебы) & 3 & 12 & 9,64 & 2,43 \\
\hline Проявление агрессии в ДВ & 3 & 12 & 9,17 & 2,07 \\
\hline Интегральный показатель переживания ДВ & 5,17 & 11,67 & 9,27 & 1,37 \\
\hline
\end{tabular}

Показатели тайм-синдрома находятся в зоне высоких значений (более 9 баллов): переживание дефицита времени у выборки студентов выражено значительно. Это обусловлено спецификой обучения, описанной выше. Зависимость от учебы, как проявление вынужденного трудоголизма, имеет наибольшее значение: студенты переживают, что время на выполнение учебных дел занимает большую часть времени их жизнедеятельности $(9,64$ балла). 


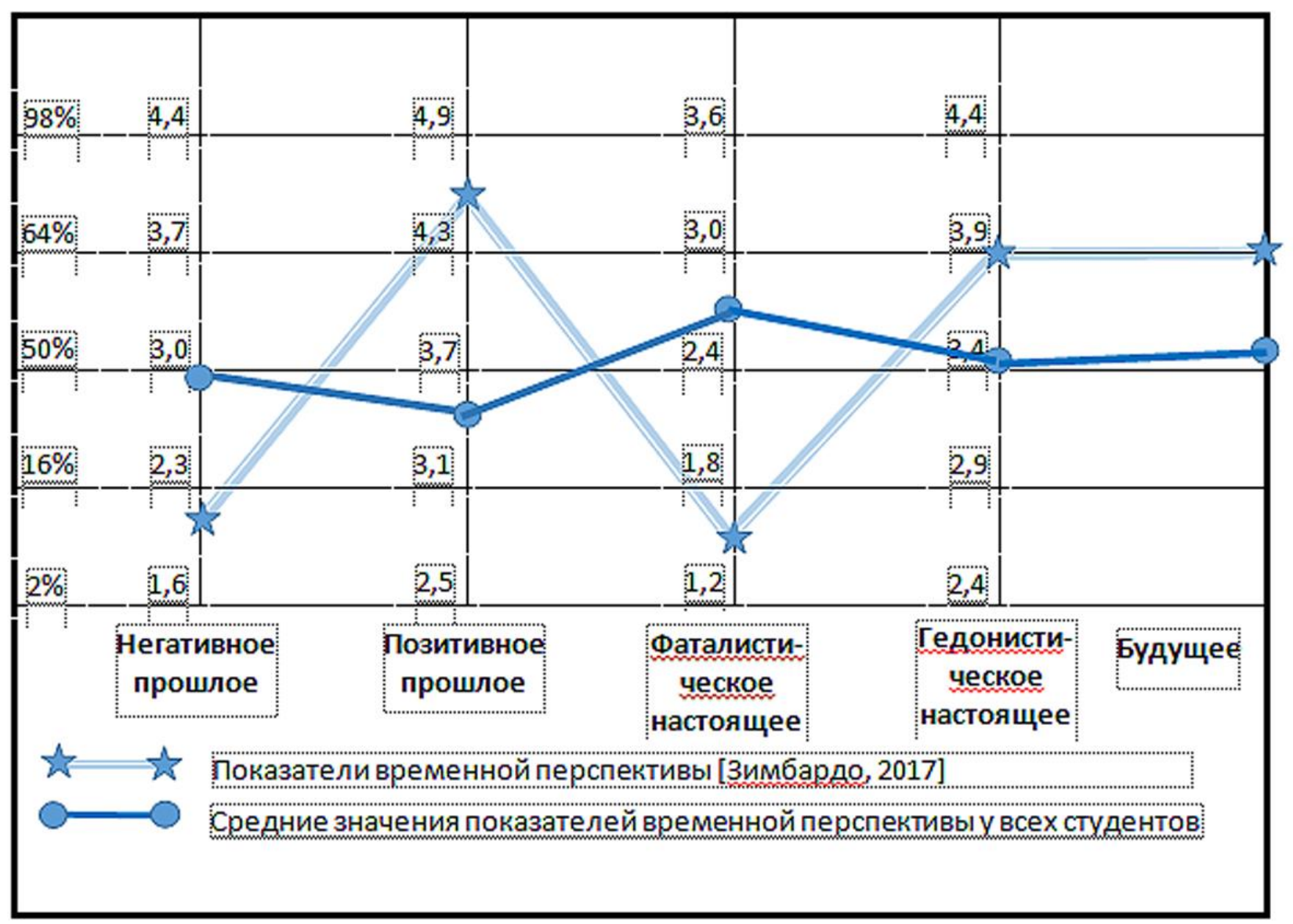

Рис. 1. Показатели временной перспективы у выборки студентов (N=69) и показатели временной перспективы, полученные Ф. Зимбардо [5]

Факторизация внутри рассматриваемых уровней переживания времени показала, как формируется специфика переживания времени у студентов (табл. 2-4).

Таблица 2

Факторизация показателей временной перспективы

\begin{tabular}{|c|c|c|}
\hline $\begin{array}{c}\text { Фактор 1.1 } \\
\text { Позитивное прошлое как } \\
\text { предиктор гедонистического } \\
\text { настоящего }\end{array}$ & $\begin{array}{c}\text { Фактор 1.2 } \\
\text { Негативное прошлое } \\
\text { как предиктор } \\
\text { фаталистического } \\
\text { настоящего }\end{array}$ & $\begin{array}{c}\text { Фактор 1.3 } \\
\text { Ориентация в } \\
\text { будущее }\end{array}$ \\
\hline Вес фактора $-1,57$ & Вес фактора $-1,44$ & Вес фактора $-1,16$ \\
\% дисперсии $-31,44$ & \% дисперсии $-28,72$ & дисперсии - 23,10\% \\
\hline Позитивное прошлое $(, 85)$ & Негативное прошлое (,94) & Будущее (,95) \\
Гедонистическое настоящее & Фаталистическое настоящее & \\
$(, 82)$ & $(, 65)$ & \\
\hline
\end{tabular}


Таблица 3

Факторизация показателей шкал переживания учебного времени

(психологического времени)

\begin{tabular}{|c|c|c|}
\hline $\begin{array}{c}\text { Фактор } 2.1 \\
\text { Переживание времени как } \\
\text { неприятного } \\
\text { раздробленного и } \\
\text { неорганизованного }\end{array}$ & $\begin{array}{c}\text { Фактор } 2.2 \\
\text { Эмоциональное } \\
\text { переживание } \\
\text { напряженности времени }\end{array}$ & $\begin{array}{c}\text { Фактор } 2.3 \\
\text { Переживание } \\
\text { насыщенности времени } \\
\text { событиями }\end{array}$ \\
\hline $\begin{array}{c}\text { Вес фактора }-2,13 \\
\% \text { дисперсии }-21,26\end{array}$ & $\begin{array}{c}\text { Вес фактора - 1,77 } \\
\text { \% дисперсии - 17,67 }\end{array}$ & $\begin{array}{c}\text { Вес фактора }-1,76 \\
\% \text { дисперсии - 17,62 }\end{array}$ \\
\hline $\begin{array}{c}\text { Неприятное }(, 79) \\
\text { Раздробленное }(, 75) \\
\text { Скачкообразное }(, 56) \\
\text { Неорганизованное }(, 53)\end{array}$ & $\begin{array}{c}\text { Предельное }(-, 76) \\
\text { Быстрое }(, 60) \\
\text { Сжатое }(-, 57) \\
\text { Ограниченное }(-, 56)\end{array}$ & $\begin{array}{c}\text { Разнообразное }(, 81) \\
\text { Насыщенное }(, 77)\end{array}$ \\
\hline
\end{tabular}

Факторизация показателей временной перспективы выявила значительную роль отношения к своему опыту в формировании представления о настоящем, на фоне которого разворачивается учебный процесс (табл. 2). Факторы показателей психологического времени отличаются разнонаправленным эмоциональным отношением к учебному времени: от отношения к нему как к неприятному до переживания насыщенности времени актуальными событиями (табл. 3). При факторизации показателей ситуативно обусловленного переживания времени выделились факторы, отличающиеся по силе проявлений эмоционального отношения к ситуации дефицита времени: от переживания зависимости от учебы до возможного проявления агрессии в ситуации дефицита времени (табл. 4).

Результаты вторичной факторизации стали важными для понимания целостной системы переживания времени студентами (табл. 5). Переживание своего опыта (негативно или позитивно окрашенного) формирует представление о своем настоящем и вместе с индивидуальным отношением к своему учебному времени (психологическое время) и с переживанием ситуации дефицита времени образует два специфических фактора настоящего времени. 
Таблица 4

Факторизация показателей тайм-синдрома

\begin{tabular}{|c|c|}
\hline $\begin{array}{c}\text { Фактор } 3.1 \\
\text { Переживание ограниченности времени } \\
\text { и зависимости от учебы в условиях } \\
\text { дефицита времени }\end{array}$ & $\begin{array}{c}\text { Фактор } 3.2 \\
\text { Агрессия и непродуктивность } \\
\text { использования времени в условиях } \\
\text { дефицита времени }\end{array}$ \\
\hline $\begin{array}{c}\text { Вес фактора }-2,08 \\
\% \text { дисперсии }-34,59\end{array}$ & $\begin{array}{c}\text { Вес фактора }-1,63 \\
\text { \% дисперсии -27,19 }\end{array}$ \\
\hline $\begin{array}{c}\text { Переживание ограниченности }(, 86) \\
\text { Переживание напряженности }(, 84) \\
\text { Переживание зависимости от учебы }(, 57)\end{array}$ & $\begin{array}{c}\text { Агрессия }(, 82) \\
\text { Непродуктивность использования личного } \\
\text { времени }(, 61) \\
\text { Эмоциональность переживания времени }(, 55)\end{array}$ \\
\hline
\end{tabular}

Первый фактор образовали три первичных фактора, включающие показатели временной перспективы, психологического времени и переживание дефицита учебного времени: переживание прошлого как позитивного опыта формирует гедонистическое настоящее, которое сопровождается переживанием дискретности и ограниченности учебного времени, а также переживанием агрессии и осознанием непродуктивности использования своего времени (вес фактора - 1,64, \% дисперсии - 20,54).

Второй фактор также выявил роль переживания прошлого, но как негативного опыта, в формировании фаталистического настоящего; фаталистическое настоящее сопровождается ситуативным переживанием зависимости от учебы при дефиците/цейтноте времени (вес фактора - 1,56, \% дисперсии - 19,54). Данный фактор не отражает отношение студентов к своему актуальному учебному времени.

Третий фактор образовали первичные факторы - «Будущее» и «Эмоциональное переживание учебного времени как насыщенного разнообразными событиями» (вес фактора - 1,49 \%, дисперсии - 18,66). Представление о будущем сопровождается только особенностями переживания времени учебной деятельности (факторы психологического времени). 
Таблица 5

Факторы ситуативно-личностной структуры времени у студентов

\begin{tabular}{|c|c|c|}
\hline Фактор 1' & Фактор 2' & Фактор 3' \\
\hline $\begin{array}{c}\text { Позитивное прошлое как } \\
\text { предиктор гедонистического } \\
\text { настоящего; } \\
\text { дискретность течения } \\
\text { учебного времени; в } \\
\text { ситуации дефицита времени } \\
\text { выраженная агрессия и } \\
\text { осознание непродуктивности } \\
\text { использования личного } \\
\text { времени }\end{array}$ & $\begin{array}{c}\text { Переживание негативного } \\
\text { прошлого как предиктор } \\
\text { фаталистического } \\
\text { настоящего; } \\
\text { в ситуации дефицита } \\
\text { времени переживание } \\
\text { ограниченности времени и } \\
\text { зависимости от учебы }\end{array}$ & \begin{tabular}{|c|} 
Переживание будущего; \\
эмоциональное \\
переживание учебного \\
времени как \\
насыщенного \\
разнообразными событиями
\end{tabular} \\
\hline $\begin{array}{c}\text { Вес фактора - 1,64 } \\
\% \text { дисперсии - 20,54 }\end{array}$ & $\begin{array}{c}\text { Вес фактора - 1,56 } \\
\text { \% дисперсии - 19,54 }\end{array}$ & $\begin{array}{c}\text { Вес фактора - 1,49 } \\
\% \text { дисперсии - 18,66 }\end{array}$ \\
\hline $\begin{array}{c}\text { Фактор 1.1. } \\
\text { Позитивное прошлое как } \\
\text { предиктор гедонистического } \\
\text { настоящего }(, 77)\end{array}$ & $\begin{array}{c}\text { Фактор 1.2. } \\
\text { Негативное прошлое как } \\
\text { предиктор фаталистического } \\
\text { настоящего }(, 81)\end{array}$ & $\begin{array}{c}\text { Фактор } 1.3 . \\
\text { Будущее }(, 84)\end{array}$ \\
\hline $\begin{array}{c}\text { Фактор } 3.2 . \\
\text { Агрессия и непродуктивность } \\
\text { использования времени } \\
(-, 74)\end{array}$ & $\begin{array}{c}\text { Фактор } 3.2 . \\
\text { Переживание ограниченности } \\
\text { времени и зависимости от } \\
\text { учебы }(, 78)\end{array}$ & $\begin{array}{c}\text { Фактор 2.3. } \\
\text { Переживание насыщенности } \\
\text { времени событиями }(, 73)\end{array}$ \\
\hline $\begin{array}{c}\text { Фактор } 2.1 . \\
\text { Переживание времени как } \\
\text { неприятно-ограниченного и } \\
\text { дискретного }(, 45)\end{array}$ & & $\begin{array}{c}\text { Фактор } 2.2 . \\
\text { Эмоциональное переживание } \\
\text { напряженности времени } \\
(, 42)\end{array}$ \\
\hline
\end{tabular}

Полученная ситуативно-личностная структура переживания времени студентами, с одной стороны, вполне логично показала первостепенную роль временной перспективы как отношения человека ко времени своей жизни (обусловленность представлений о настоящем прошлыми событиями, спецификой настоящего и устремленность в будущее), с другой - выявила роль и место переживания учебного времени в жизнедеятельности студентов. Переживание насыщенности и полноты учебного времени помогает создавать образ своего будущего независимо от переживания своего прошлого как негативного, восприятия настоящего как фаталистического и ситуативного переживания кратковременных трудностей (дефицита времени). Таким образом, насыщенное разнообразными событиями учебное время является условием построения будущего, а также - мотивационным ресурсом учебной успешности. 


\section{Список литературы}

1. Василюк Ф.Е. Психология переживаний. - 1984. - Москва: Издательство Моск. Ун-та. - 200 с.

2. Рубинштейн С. Л. Человек и мир. - Санкт-Петербург: Издательство «Питер». - 224 с.

3. Головаха Е. А., Кроник А. А. Психологическое время личности. Москва: Издательство «Смысл». - 2008. - 283 с.

4. Широкая М. Ю. «Пространство времени» как актуальная проблема психологии труда // Мир психологии. - 2019. - № 2 (98). - С. 150-160.

5. Деревянко Ю. П. Особенности переживания времени в студенческом возрасте. Дисс...канд.психол.наук: 19.00.13. - Москва. - 2011.

6. Зимбардо Ф., Сворд Р., Сворд Р. Время как лекарство. - СанктПетербург: Издательство «Питер». - 2017. - 288 с.

7. Водопьянова Н. Е. Стресс-менеджмент: учебник для бакалавриата и магистратуры. - 2018. - Москва: Издательство «Юрайт». - 283 с.

(C) М.Ю. Широкая, 2020 